\title{
Redox-Responsive Nanophotosensitizer Composed of Chlorin e6-Conjugated Dextran for Photodynamic Treatment of Colon Cancer Cells
}

\author{
Chong Woo Chu, ${ }^{1}$ Je Ho Ryu, ${ }^{1}$ Young-IL Jeong, ${ }^{2}$ Tae Won Kwak, ${ }^{2}$ Hye Lim Lee, ${ }^{2}$ \\ Hyun Yul Kim, ${ }^{1}$ Gyung Mo Son, ${ }^{1}$ Hyung Wook Kim, ${ }^{3}$ and Dae Hwan Kang ${ }^{2,3,4}$ \\ ${ }^{1}$ Department of Surgery, Pusan National University Yangsan Hospital, Gyeongnam 626-770, Republic of Korea \\ ${ }^{2}$ Biomedical Research Institute, Pusan National University Hospital, Pusan 602-739, Republic of Korea \\ ${ }^{3}$ Department of Internal Medicine, Pusan National University Yangsan Hospital, Gyeongnam 626-770, Republic of Korea \\ ${ }^{4}$ Research Institute for Convergence of Biomedical Science and Technology, Pusan National University Yangsan Hospital, \\ Gyeongnam 626-770, Republic of Korea
}

Correspondence should be addressed to Je Ho Ryu; jehoryu@outlook.kr and Dae Hwan Kang; sulsulpul@naver.com

Received 6 September 2015; Revised 26 October 2015; Accepted 27 October 2015

Academic Editor: David Cornu

Copyright ( $) 2016$ Chong Woo Chu et al. This is an open access article distributed under the Creative Commons Attribution License, which permits unrestricted use, distribution, and reproduction in any medium, provided the original work is properly cited.

\begin{abstract}
We synthesized dextran-chlorin e6 conjugates having disulfide linkage for specific targeting of colonic region and cancer cells. Reductive end group of dextran was treated with sodium borocyanohydride and conjugated with cystamine. Cystamine end group was conjugated with carboxylic acid of chlorin e6 (DEX6ss). DEX6ss conjugates were formed as spherical nanoparticles with small sizes less than $100 \mathrm{~nm}$. Chlorin e6 (Ce6) was specifically released from DEX6ss nanoparticles in the presence of dextranase or glutathione (GSH), indicating that DEX6ss nanoparticles have responsiveness against dextranase and redox-environment. In darktoxicity test using normal cells and cancer cells, Ce6 and DEX6ss nanoparticles were practically nontoxic. Intracellular delivery of DEX6ss nanoparticles was significantly improved compared to Ce6 itself. DEX6ss nanoparticles achieved significantly higher ROS production and phototoxicity against HCT116 colon cancer cells than Ce6 itself. Furthermore, DEX6ss nanoparticles showed enhanced tumor targeting efficiency and longer retention in the tumor tissues at in vivo animal study with HCT116 tumorbearing mice. Furthermore, DEX6ss nanoparticles have responsiveness against colonic enzyme, dextranase, indicating that they have potential of colon-specific delivery and dextranase-specific drug delivery capacity. We fabricated colon-specific and tumortargetable nanophotosensitizer using DEX6ss conjugates. They showed improved cellular uptake ratio, phototoxicity, and colonspecificity. We suggest that DEX6ss nanoparticles can be considered as a promising candidate for PDT of colon cancer.
\end{abstract}

\section{Introduction}

Photodynamic therapy (PDT) is one of the palliative therapies for the treatment of various malignant and nonmalignant disorders [1-7]. Since PDT is composed of photosensitizer, specific light source, and oxygen, it is believed to be safe and nontoxic against human body $[3,4,6,7]$. Practically, photosensitizer is specifically activated under irradiated condition using specific light sources and then generates reactive oxygen species (ROS) inordinately. Thus, overproduction of ROS induces apoptosis or necrosis of cancer cells [8-11]. The clinical efficacy of PDT is significantly dependent on the photosensitizer absorption/penetration into disease tissues, the penetration depth of light source, and the availability of ROS generation $[9,10]$. Among various photosensitizers, Ce6 has been extensively investigated due to its superior properties [8, 12-14]. For example, Ce6 penetrates tissue layer deeper than conventional PS and it is activated by near infrared wavelengths [8]. Since light source with near infrared wavelengths can penetrate tissues deeper, penetration depth and light source of photosensitizer are also considered important for clinical application. From these characteristics, PDT 
can be considered a suitable treatment for gastrointestinal cancers such as colon cancer and cholangiocarcinoma $[4,6$, 15]. The PDT efficacy is principally influenced by localization of photosensitizer into target tissues and intracellular delivery [8]. However, most photosensitizers have lack of specificity against tumor tissues and rapidly cleared from the target site $[8,16,17]$.

Polymer-based delivery systems have been extensively investigated to improve PDT efficacy and to minimize drawbacks of conventional photosensitizer [8, 11, 18-21]. Hydrophilic polymers such as polyvinylpyrrolidone (PVP) and pluronic F127 showed effectiveness in enhancing solubility, intracellular trafficking, and photodynamic treatment of photosensitizer [18, 21]. We also reported that polyvinyl alcohol (PVA) has effectiveness in photosensitivity increase of photosensitizer against cholangiocarcinoma cells [11]. In this report, PVA nanofiber improves photosensitizer delivery to the cholangiocarcinoma cells and effectively inhibited viability of cancer cells. Furthermore, nanoparticles based on ursodeoxycholic acid-modified chitosan also showed enhanced intracellular delivery of Ce6, ROS generation, and photosensitivity against HuCC-T1 cholangiocarcinoma cells [8].

In this study, we synthesized Ce6-conjugated dextran to improve delivery efficacy and photosensitivity against colon cancer cells. Dextran is a hydrophilic polysaccharide composed of 1,6-/1,3-glucosidic linkages. Dextran has been extensively used in the biomedical field due to its biocompatibility and immune-neutrality [22-26]. In particular, dextran is specifically degraded in the colonic region due to the existence of dextranase [25]. We conjugated Ce6 with terminal group of dextran using disulfide linkage (abbreviated as DEX6ss). Then, intracellular delivery capacity, ROS production, and photosensitivity of DEX6ss were investigated with HCT116 human colon carcinoma cells in vitro and in vivo.

\section{Materials and Methods}

2.1. Materials. Ce6 was obtained from Frontier Scientific, Inc. (Logan, UT, USA). N-(3-Dimethylaminopropyl)- $\mathrm{N}^{\prime}$ ethylcarbodiimide hydrochloride (EDAC), N-hydroxysuccinimide (NHS), cystamine dihydrochloride, dimethyl sulfoxide (DMSO), chloroform, $2^{\prime}, 7^{\prime}$-dichlorofluorescein diacetate (DCFH-DA), triethylamine (TEA), GSH, sodium cyanoborohydride, and 3-[4,5-dimethylthiazol-2-yl]-2,5diphenyltetrazolium bromide (MTT) were purchased from Sigma-Aldrich Co. (St. Louis, MO, USA). Dialysis membrane (molecular weight cut-off: $2,000 \mathrm{~g} / \mathrm{mol}, 8,000 \mathrm{~g} / \mathrm{mol}$ ) was purchased from Spectrum Lab., Inc. (CA, USA). All organic solvents were used as HPLC grade. Dextran from Leuconostoc spp. (molecular weight (MW) from manufacturer's data: $6,000 \mathrm{~g} / \mathrm{mol}$ ) was purchased from Sigma-Aldrich Co. (St Louis, MO, USA). In a previous report, weight-average MW $\left(M_{w}\right)$, number MW $\left(M_{n}\right)$, and polydispersity index (PDI) of dextran were $4,800 \mathrm{~g} / \mathrm{mol}, 4,370 \mathrm{~g} / \mathrm{mol}$, and 1.098 , respectively [23].

\subsection{Synthesis and Characterization of DEX6ss Conjugates}

Dextran-Cystamine Conjugates. Synthesis scheme was illustrated in Figure 1. Dextran-cystamine conjugates were synthesized as reported previously [23]. $600 \mathrm{mg}$ of dextran was dissolved in $10 \mathrm{~mL}$ DMSO and then sodium cyanoborohydride ( $314 \mathrm{mg}, 5 \mathrm{mM}$ ) in $3 \mathrm{~mL}$ water was added following magnetic stirring for $24 \mathrm{~h}$. After that, reactants were poured into excess amount of methanol to precipitate dextran. Precipitates were filtered out and washed more than three times with methanol. Filtered products were dried under vacuum at room temperature for $24 \mathrm{~h}$. Dried dextran products were dissolved in $10 \mathrm{~mL}$ DMSO. Cystamine dihydrochloride (450 mg) was separately dissolved in $5 \mathrm{~mL}$ of DMSO/water mixtures (deionized water/DMSO $(2 / 3, \mathrm{v} / \mathrm{v})$ ) and then trace amount of TEA was added. Then, this solution was mixed with dried dextran in DMSO solution. This reaction was magnetically stirred for $48 \mathrm{~h}$ at room temperature. After that, reactants were put into dialysis membrane (MWCO 2,000 g/mol) and then dialyzed against deionized water for 2 days to remove byproducts. Deionized water was exchanged at intervals of $3 \mathrm{~h}$. Resulting solution was lyophilized for 3 days and then lyophilized solid (dextran-cystamine conjugates, DEX6ss in Figure 1) was stored under $-20^{\circ} \mathrm{C}$ until use.

DEX6ss Conjugates. Ce6 (60 mg, $0.1 \mathrm{mM}$ ) was dissolved in $4 \mathrm{~mL}$ DMSO. 1.2 equivalents of EDAC and NHS was added to Ce6/DMSO solution and then stirred magnetically for $6 \mathrm{~h}$ to make NHS-activated Ce6 (Ce6-NHS). After that, DEX6ss (480 mg) dissolved in $5 \mathrm{~mL}$ DMSO was mixed with Ce6NHS. This reaction was further stirred magnetically for $24 \mathrm{~h}$. After that, reaction solution was put into dialysis membrane (MWCO 2,000 g/mol) and then dialyzed against water for 2 days with exchange of water at intervals of $3 \mathrm{~h}$. Dialyzed solution was lyophilized for 3 days. Lyophilized solid was precipitated into excess amount of chloroform/methanol mixture $(1 / 1, v / v)$ to remove unreacted Ce6 and then filtered out. Filtered products were washed with chloroform/methanol mixture $(1 / 1, v / v)$ for three times. Resulting products was dried under vacuum for 3 days at room temperature. After that, dried solid was directly reconstituted into water to form nanoparticles with sonication $(1 \mathrm{~s} \times 10)$ using ultrasonicator (Sonics, VCX-750, Son-ics \& Materials Inc., CT, USA). This solution was introduced into dialysis membrane (MWCO $8,000 \mathrm{~g} / \mathrm{mol}$ ) and then dialyzed against deionized water for $9 \mathrm{~h}$ with magnetic stirring to remove unreacted dextran or DEX6ss. Deionized water was exchanged at $1 \mathrm{~h}$ intervals during dialysis procedure. Following this, dialyzed solution was lyophilized for 2 days. The yield of final products was approximately $78 \%$ [the yield of final products $=(($ weight of Ce6 + weight of dextran)/weight of final products) $\times$ 100]. All procedures for synthesis of DEX6ss conjugates were performed at dark condition.

2.3. Fabrication of Nanoparticles. $20 \mathrm{mg}$ of DEX6ss conjugates was dissolved in $2 \mathrm{~mL}$ DMSO and then dropped into $10 \mathrm{~mL}$ deionized water. This solution was put into dialysis membrane (MWCO 2,000 g/mol) and then dialyzed against deionized water for $24 \mathrm{~h}$ with exchange of water at intervals 

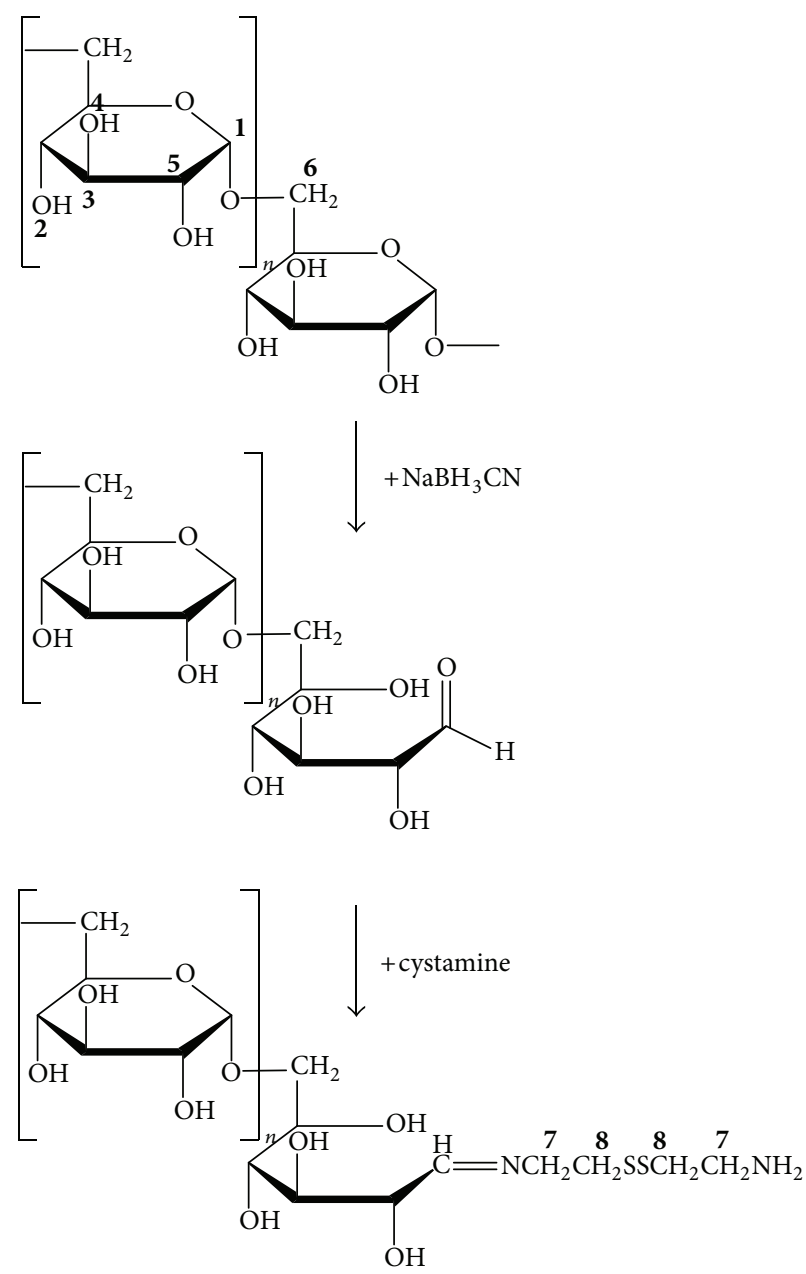

Dextran-cystamine conjugates
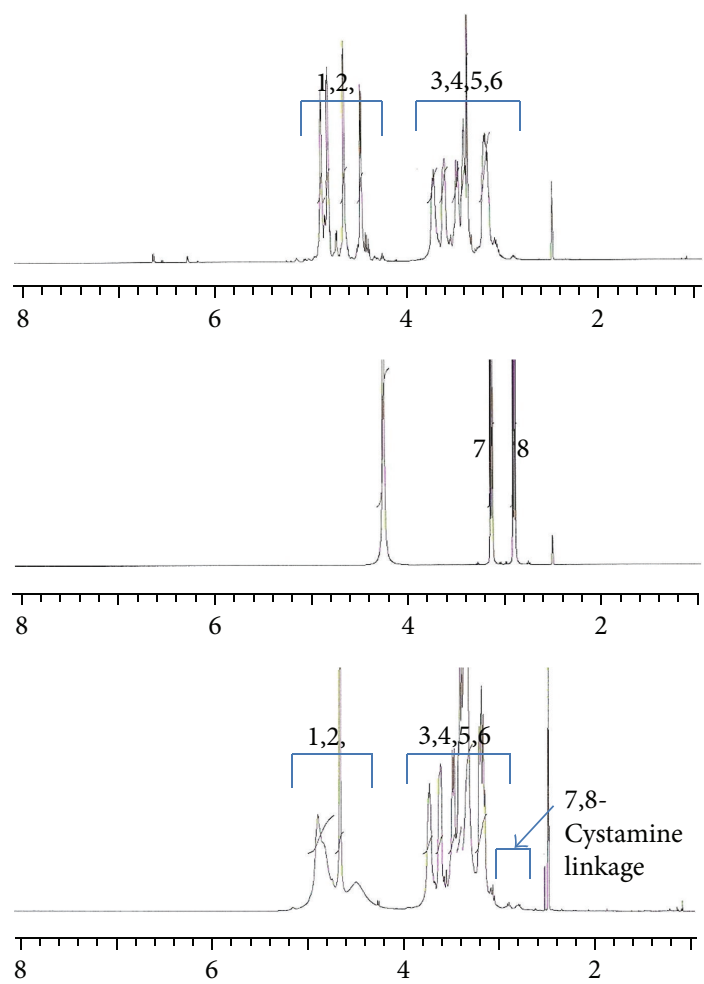

Figure 1: Synthesis scheme and ${ }^{1}$ H NMR spectra of DEX6ss conjugates.

of $2 \sim 3 \mathrm{~h}$. After that, resulting solution was used for further experiments or stored in refrigerator until use.

2.4. Characterization of DEX6ss Conjugates and Their Nanoparticles. To verify chemical structure of DEX6ss, ${ }^{1} \mathrm{H}$ nuclear magnetic resonance (NMR) (500 MHz superconducting Fourier transform-NMR spectrometer, Varian Unity Inova; Varian Inc., Santa Clara, CA, USA) spectroscopy was employed.

The morphological observation of DEX6ss nanoparticles was performed with transmission electron microscope (TEM) (H-7600, Hitachi Instruments Ltd., Tokyo, Japan). DEX6ss nanoparticles in deionized water were dropped onto a carbon film coated copper grid. Then, this was dried at room temperature for $12 \mathrm{~h}$ and then one drop phosphotungstic acid $(0.1 \% \mathrm{w} / \mathrm{w}$ in deionized water) was dropped to stain nanoparticles negatively. The observation was performed at $80 \mathrm{kV}$.

Hydrodynamic diameter of DEX6ss nanoparticles was analyzed with Nano-ZS (Malvern, Worcestershire, UK).
Nanoparticle solution was adjusted to less than $0.1 \mathrm{wt} \%$ and then measured at room temperature.

2.5. Fluorescence Properties and Ce6 Release Study of DEX6ss Nanoparticles. The fluorescence emission spectra of DEX6ss nanoparticles were investigated with multifunctional microplate reader (Infinite M200 pro microplate reader, Tecan, Männedorf, Switzerland) between $500 \mathrm{~nm}$ and $800 \mathrm{~nm}$ (excitation wavelength: $400 \mathrm{~nm}$ ). To study the effect of dextranase or GSH, DEX6ss nanoparticles were prepared as described above and diluted with PBS ( $\mathrm{pH} 7.4,0.01 \mathrm{M})$. This solution was mixed with dextranase and then incubated for $3 \mathrm{~h}$ at $37^{\circ} \mathrm{C}$. For GSH effect, DEX6ss nanoparticles were adjusted to a concentration of $1 \mathrm{mg}$ DEX6ss $/ \mathrm{mL}$ and then incubated for $90 \mathrm{~min}$ at $37^{\circ} \mathrm{C}$. These solutions were measured with Maestro 2 small animal imaging instrument (Cambridge Research and Instrumentation Inc., MA 01801, USA).

To evaluate Ce6 release properties, DEX6ss nanoparticle solution prepared as described above was adjusted to $1 \mathrm{mg} / \mathrm{mL}$ and $5 \mathrm{~mL}$ of this solution was introduced into 
dialysis tube (MWCO, 2,000 g/mol) with or without dextranase (100 unit) and GSH $(10 \mathrm{mM})$. After that, dialysis tube was introduced into $100 \mathrm{~mL}$ bottle with $45 \mathrm{~mL}$ phosphate buffered saline (PBS, $\mathrm{pH} 7.4,0.01 \mathrm{M}$ ) and then bottle was incubated in the shaking incubator $\left(100 \mathrm{rpm}, 37^{\circ} \mathrm{C}\right)$. At specific time intervals, whole media were taken to measure released Ce6 concentration and replaced with fresh PBS. Ce6 concentration was measured with at an excitation wavelength of $407 \mathrm{~nm}$ and an emission wavelength of $664 \mathrm{~nm}$ using an Infinite M200 pro microplate reader (Tecan). All experiments were triplicated and expressed as the value of mean \pm standard deviation.

2.6. Cell Culture. CCD-986Sk human normal skin fibroblast cells and HCT116 human colon carcinoma cells were obtained from Korean Cell Line Bank (Seoul, Korea). CCD-986Sk cells, RAW264.7 cells, and NIH3T3 cells were cultured with DMEM (Gibco, Grand Island, NY, USA) supplemented with $10 \%$ fetal bovine serum (FBS) (Invitrogen) and $1 \%$ antibiotics. HCT116 cells were cultured with RPMI1640 (Gibco, Grand Island, NY, USA) supplemented with $10 \%$ fetal bovine serum (FBS) (Invitrogen) and $1 \%$ antibiotics. Caco-2 cells were cultured with DMEM (Gibco, Grand Island, NY, USA) supplemented with $10 \%$ fetal bovine serum (FBS) (Invitrogen) and $1 \%$ antibiotics. All cell lines were cultured at $37^{\circ} \mathrm{C}$ in a humidified atmosphere with $5 \% \mathrm{CO}_{2}$.

\subsection{Dark Toxicity and Phototoxicity of Ce6 and Pe6 Nanopar-} ticles. For dark toxicity, $3 \times 10^{4}$ cells seeded in each well of 96-well plates were cultured overnight. Cells were washed with PBS. Ce6 dissolved in DMSO was diluted with culture medium at least 100 times. DEX6ss nanoparticles prepared as described above were sterilized with $0.45 \mu \mathrm{m}$ syringe filter and then diluted with culture medium. Ce6 or DEX6ss nanoparticles in serum-free medium were treated to cells for $2 \mathrm{~h}$. Cells were washed with PBS two times to remove floating nanoparticles and then replaced with fresh culture media following with incubation at $37^{\circ} \mathrm{C}\left(5 \% \mathrm{CO}_{2}\right.$ incubator $)$ for additional $24 \mathrm{~h}$. Cell viability was measured using the MTT assay. MTT assay was performed as follows [23]: briefly, $25 \mu \mathrm{L}$ MTT reagent $(3 \mathrm{mg} / \mathrm{mL}$ in PBS) was added to 96 -well plates and then incubated at $37^{\circ} \mathrm{C}$ for an additional $4 \mathrm{~h}$. After that, $100 \mu \mathrm{L}$ of lysis buffer solution (10\% sodium dodecyl sulfate in $0.01 \mathrm{~N} \mathrm{HCl}$ ) was added and incubated for $18 \mathrm{~h}$. Cell viability was assessed with absorbance measurement at $570 \mathrm{~nm}$ using an Infinite M200 pro microplate reader. All procedure was performed in dark condition.

For phototoxicity, $3 \times 10^{4}$ HCT116 cells in 96-well plates were treated with various concentrations of Ce6 and DEX6ss nanoparticles for $2 \mathrm{~h}$. Following this, cells were washed with PBS twice to remove floating nanoparticles and then replaced with $100 \mu \mathrm{L}$ of fresh serum-free media. Then, cells were irradiated with expanded homogenous beam $(664 \mathrm{~nm}, \mathrm{SH}$ Systems, Gwangju, Korea) at a light dose of $2.0 \mathrm{~J} / \mathrm{cm}^{2}$ (the signal was measured using a photoradiometer (DeltaOhm, Padova, Italy)). After irradiation, the cells were incubated for additional $24 \mathrm{~h}$. Cell viability was determined using the MTT assay.
2.8. Intracellular Uptake of Ce6. HCT116 cells in a 96-well plate were treated with various concentrations of Ce6 or DEX6ss nanoparticles in serum-free media at $37^{\circ} \mathrm{C} .2 \mathrm{~h}$ later, cells were washed twice with PBS and solubilized in $50 \mu \mathrm{L}$ of lysis buffer (GenDEPOT, Barker, TX, USA). Relative Ce6 uptake was evaluated at an excitation wavelength of $407 \mathrm{~nm}$ and an emission wavelength of $664 \mathrm{~nm}$ using an Infinite M200 pro microplate reader (Tecan).

Observation of Ce6 uptake was performed with fluorescence microscope (Eclipes 80i; Nikon, Tokyo, Japan) equipped with a $590 \mathrm{~nm}$ excitation filter and a $615 \mathrm{~nm}$ filter. 2 $\times 10^{5}$ HCT116 cells were seeded onto a cover glass in a 6-well plate and then treated with Ce6 or DEX6ss nanoparticles for $1 \mathrm{~h}$ in serum-free media. Following this, media was discarded and the cells were washed with PBS. Cells were fixed with immobilization solution (Immunomount, thermo Electron Co., Pittsburgh, PA, USA). The cells were observed with confocal laser scanning microscope (CLSM, TCS-SP2; Leica, Wetzlar, Germany).

2.9. ROS Assay. ROS generation from irradiated cells was evaluated by DCFH-DA method as reported previously [8]. HCT116 cells were treated with Ce6 or DEX6ss nanoparticles with DCFH-DA (final concentration: $20 \mu \mathrm{M}$ ) in phenol redfree RPMI media and then incubated at $37^{\circ} \mathrm{C}$. $2 \mathrm{~h}$ later, the cells were washed with PBS two times and then $100 \mu \mathrm{L}$ of fresh phenol red-free RPMI media was added to each well. Then, cells were irradiated at $664 \mathrm{~nm}\left(2.0 \mathrm{~J} / \mathrm{cm}^{2}\right)$ and fluorescence intensity was measured at an excitation wavelength of $485 \mathrm{~nm}$ and emission wavelength of $535 \mathrm{~nm}$ using an Infinite M200 pro microplate reader (Tecan).

\subsection{In Vivo Fluorescence Imaging with HCT116 Tumor-} Bearing Mouse. $1 \times 10^{6}$ HCT116 cells were subcutaneously implanted on the back of the nude BALb/C mice. When solid tumor in the back of mice reached $4 \sim 5 \mathrm{~mm}$ in diameter (approximately five weeks later), Ce6 or DEX6ss nanoparticles were injected subcutaneously beside solid in the back of mice. Injection volume was $100 \mu \mathrm{L}$. $24 \mathrm{~h}$ after injection, mouse was observed with Maestro 2 small animal imaging instrument. For observation of mouse tumor tissue, mice were sacrificed $24 \mathrm{~h}$ after i.v. injection and tumor tissues were extracted.

2.11. PDT Effect with HCT116 Tumor-Bearing Mouse. To evaluate PDT efficacy of DEX6ss nanoparticles in vivo, $1 \times$ $10^{6}$ HCT116 cells were subcutaneously implanted on the back of the nude BALb/C mice. When solid tumor in the back of mice reached larger than $3 \sim 4 \mathrm{~mm}$ in diameter (approximately four weeks later), mice were divided to three groups (five mice per each group) as follows: control group was subcutaneously injected with $100 \mu \mathrm{L}$ of PBS. For Ce6 treatment, Ce6 dissolved in Cremophor EL/ethanol mixture (1/1) was diluted with PBS and subcutaneously injected into the back of mice. DEX6ss nanoparticles prepared as described above was sterilized with $0.45 \mu \mathrm{m}$ syringe filter and injected subcutaneously into the back of mice. All mice were irradiated $\left(2.0 \mathrm{~J} / \mathrm{cm}^{2}\right)$ at 1 day and 3 days after injection. The growth of tumor volume 
was monitored at intervals of 3 days and tumor volume was calculated with following equation (tumor volume $\left(\mathrm{mm}^{3}\right)$ $=$ length $\times$ width $^{2} / 2$ ). All animal study was carried out according to the guidelines of the Animal Treatment and Research Council of Pusan National University.

2.12. Statistical Data Analysis. Statistical analysis of the results was performed using the $t$-test with $p<0.05$ as the minimal level of significance.

\section{Results}

3.1. Synthesis of and Characterization of DEX6ss Conjugates. To synthesize DEX6ss conjugates, the reductive end of dextran was treated with $\mathrm{NaCNBH}_{3}$ and then excess amount of cystamine was added to make amine-terminated dextran as shown in Figures 1 and 2. As shown in Figure 1, intrinsic peaks of dextran and cystamine appeared at 3 5 ppm and 2.5 3.5 ppm. DEX6ss showed intrinsic peaks of dextran at $3 \sim 5 \mathrm{ppm}$ and, interestingly, peaks at $2.6 \sim 3.0 \mathrm{ppm}$ can be defined as peaks of cystamine molecules. To synthesis Ce6 at the amine end group of DEX6ss, NHS-activated Ce6 was added and conjugated to the amine group of DEX6ss as shown in Figure 2(a). Carboxyl group of $\mathrm{Ce} 6$ was reacted with EDAC/NHS to make NHS-activated Ce6 and then conjugated with cystamine group of DEX6ss. As shown in Figure 2(b), specific peaks of $\mathrm{Ce} 6$ appeared at 1 3 ppm and 6 10 ppm from ${ }^{1} \mathrm{H}$ NMR spectra of DEX6ss conjugates. These results indicated that $\mathrm{Ce} 6$ was successfully conjugated to the cystamine end group of DEX6ss conjugates. The yield of DEX6ss conjugates was approximately $78 \%(w / w)$.

3.2. Fabrication and Characterization of DEX6ss Nanoparticles. To fabricate DEX6ss nanoparticles, DEX6ss conjugates were dissolved in DMSO and then dialyzed against deionized water to form nanoparticles. As shown in Figure 3, DEX6ss nanoparticles showed spherical shapes and sizes were less than $200 \mathrm{~nm}$ (Figure 2(a)), indicating that DEX6ss conjugates can form spherical nanoparticles in the aqueous environment. When hydrodynamic diameter of DEX6ss nanoparticles was measured, average particle size of DEX6ss nanoparticles was $89 \mathrm{~nm}$ and showed narrow distribution (Figure 2(b)).

Since dextran can be degraded in the colonic region by dextranase and disulfide group can be disintegrated by GSH, dextranase was treated to DEX6ss nanoparticles to investigate the release of $\mathrm{Ce} 6$ from nanoparticles and $\mathrm{Ce} 6$ release was checked as shown in Figure 3(c). When dextranase was added to DEX6ss nanoparticles, release rate of Ce6 from DEX6ss nanoparticles was significantly increased compared to absence of dextranase. Furthermore, GSH was also adapted with DEX6ss to evaluate disconnection of disulfide linkage and then liberation of Ce6 from DEX6ss nanoparticles since GSH can cut off disulfide linkage (Figures 3(d) and 3(e)). Ce6 release was significantly increased by addition of GSH, indicating that DEX6ss nanoparticles have responsiveness against dextranase and GSH. Then, Ce6 was cleaved and released by treatment with dextranase or GSH. These results indicated that DEX6ss nanoparticles have colonic enzymeand redox-responsiveness.
3.3. Dark Toxicity, Ce6 Uptake, ROS Production, and Phototoxicity. For dark-toxicity study, Ce6 or DEX6ss nanoparticles were treated with HCT116 human colon carcinoma cells under dark condition. As shown in Figure 4, HCT116 cells treated with Ce6 and DEX6ss showed excellent viability; that is, no toxic dead cells were observed until 1.0 $\mu \mathrm{M}$ Ce6 concentrations. These results indicated that DEX6ss is safe and nontoxic in the absence of light irradiation condition under $1.0 \mu \mathrm{M}$ concentration as well as Ce6 itself.

Figure 5 showed Ce6 uptake by HCT116 human colon cancer cells. As shown in Figure 5(a), Ce6 uptake by HCT116 cells was dose-dependently increased according to the increase of Ce6 concentration. Interestingly, DEX6ss uptake was significantly higher than Ce6 itself when DEX6ss nanoparticles were treated to HCT116 cells; that is, Ce6 uptake of treatment with DEX6ss nanoparticles was approximately 5-fold compared to Ce6 itself. Figure 5(b) also showed that cells treated with DEX6ss nanoparticles revealed significantly higher fluorescence intensity than Ce6 itself. These results might be due to the fact that Ce6 uptake efficiency can be improved through conjugation with dextran using disulfide linkage and then these conjugates might increasing the cancer selectivity of Ce6. Furthermore, higher cellular uptake ratio by treatment of DEX6ss nanoparticle may induce higher ROS generation and phototoxicity. As shown in Figure 6(a), treatment of DEX6ss nanoparticles against HCT116 cells induced higher ROS generation than Ce6 treatment. ROS generation by treatment of DEX6ss was almost twofold increase compared to Ce6 itself at $1.0 \mu \mathrm{M}$. When cells were irradiated at $2.0 \mathrm{~J} / \mathrm{cm}^{2}$, cell viability was also significantly decreased by treatment of DEX6ss nanoparticles while Ce6 itself showed negligible phototoxicity as shown in Figure 6(b). Viability of HCT116 cells was higher than $90 \%$ until $1.0 \mu \mathrm{M}$ Ce6 concentration while DEX6ss treatment showed less than $30 \%$ cell viability at $1.0 \mu \mathrm{M}$ concentration.

These results indicated that DEX6ss nanoparticles have superior capacity in the cellular uptake, ROS production, and photodynamic treatment of HCT116 cells.

3.4. In Vivo Animal Study. HCT116 cells were subcutaneously injected into the back of mice as shown in Figure 7. To approve photodynamic efficacy of DEX6ss nanoparticles, HCT116 bearing mice were used as a solid tumor model. Practically, Ce6 or DEX6ss nanoparticles were also subcutaneously administered beside solid mass of HCT116 tumor because oral or local treatment of DEX6ss nanoparticles can be considered in the practical approach. The uptake of $\mathrm{Ce} 6$ or DEX6ss by solid tumor was evaluated with animal imaging study as shown in Figure 7(a). Until $3 \mathrm{~h}$ after administration of Ce6 or DEX6ss nanoparticles, fluorescence intensity of DEX6ss nanoparticle treatment in the tumor tissue was still negligible while Ce6 showed slightly higher fluorescence intensity at tumor site. However, fluorescence intensity at tumor tissue was rapidly increased $6 \mathrm{~h}$ after injection of DEX6ss nanoparticles while Ce6 treatment showed negligible fluorescence intensity at solid tumor. In particular, gap of fluorescence intensity between Ce6 treatment and DEX6ss nanoparticle treatment was significantly increased after $24 \mathrm{~h}$ of injection. These results indicated that Ce6 must be rapidly 


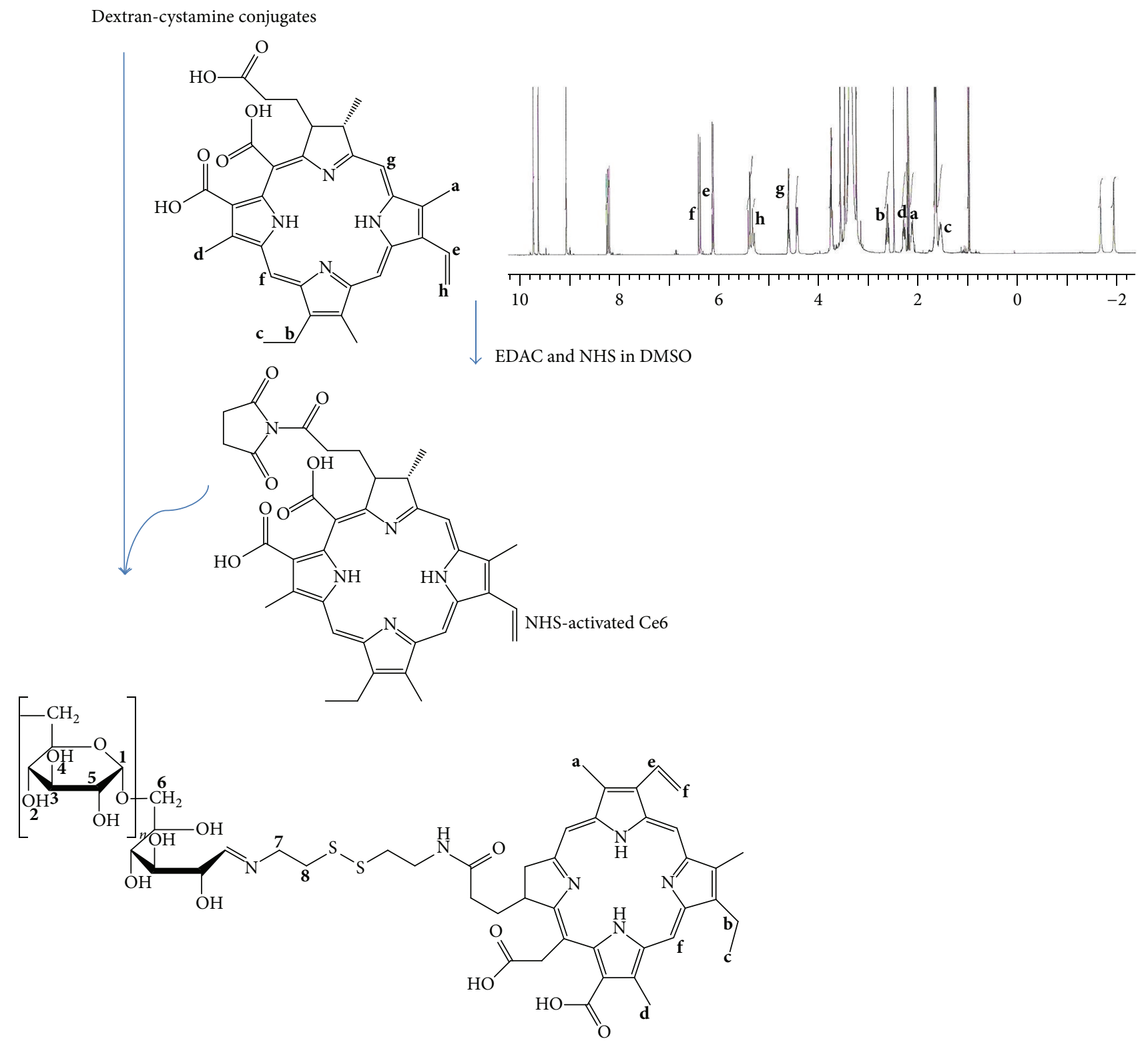

(a)

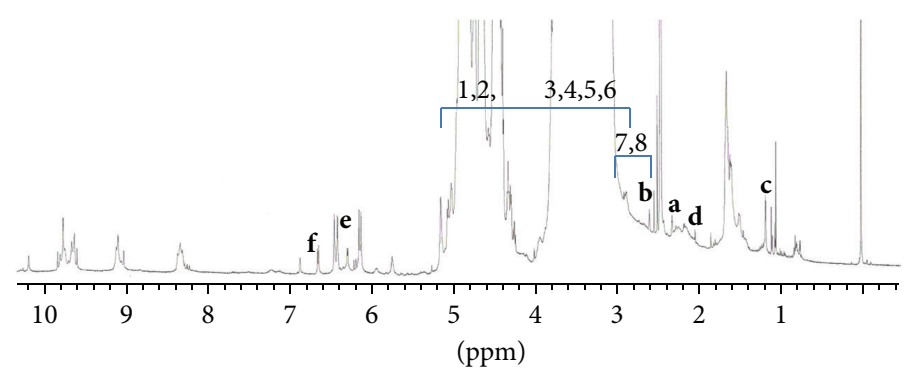

(b)

Figure 2: Synthesis scheme (a) and ${ }^{1}$ H NMR spectra (b) of DEX6ss conjugates. 

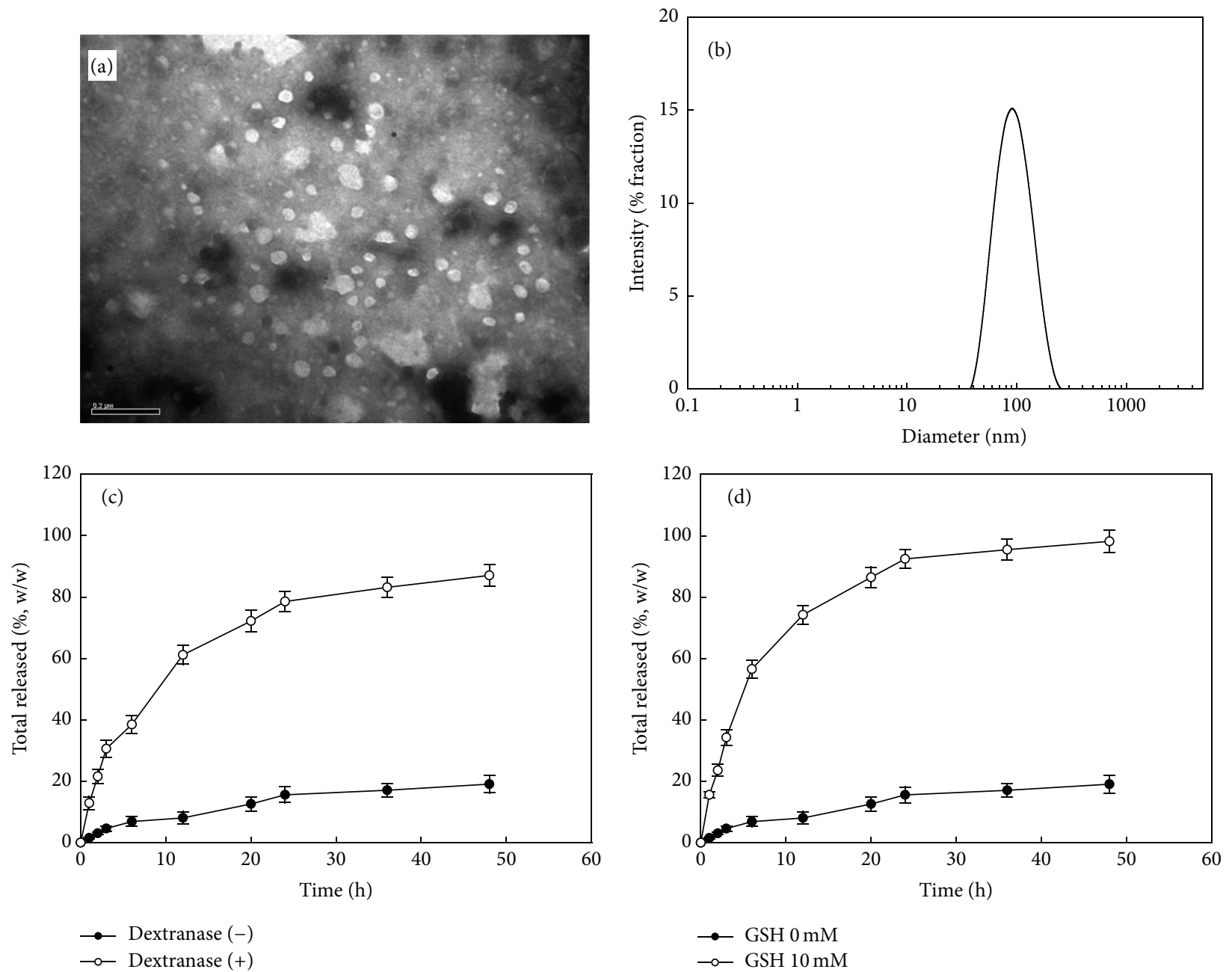

(e) GSH concentration (mM)

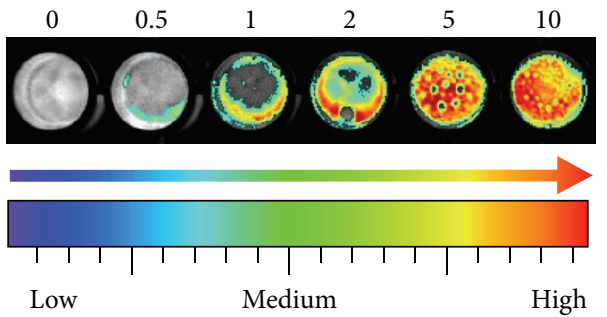

FIgURE 3: (a) TEM image and (b) typical particle size distribution of DEX6ss nanoparticles. (c) Ce6 release from DEX6ss nanophotosensitizer in the absence or presence of dextranase. For dextranase treatment, nanoparticles were incubated with dextranase in PBS (0.01 M, pH 7.4) for $3 \mathrm{~h}$ at $37^{\circ} \mathrm{C}$. (d) The effect of GSH on the Ce6 release from DEX6ss nanoparticles. (e) The effect of GSH concentration on the photophysical properties of DEX6ss nanoparticles. For GSH treatment, $1.0 \mathrm{mg}$ of DEX6ss nanoparticles was incubated with each concentration of GSH in PBS (0.01 M, pH 7.4) for $90 \mathrm{~min}$ at $37^{\circ} \mathrm{C}$. The presented data was mean \pm s.d. from three independent experiments.

cleared from tumor tissue after $6 \mathrm{~h}$ although uptake efficiency was slightly increasing at initial period $(1 \mathrm{~h} \sim 3 \mathrm{~h})$. On the other hand, DEX6ss nanoparticles showed increased tumoral uptake efficiency after $6 \mathrm{~h}$ and stayed in the tumor tissue longer than Ce6 itself. These results indicated that DEX6ss nanoparticles have superior delivery capacity of $\mathrm{Ce} 6$ for tumor tissue.
To assess PDT efficacy of DEX6ss nanoparticles, Ce6 or DEX6ss nanoparticles were subcutaneously injected beside solid tumor and mice were irradiated at days 1 and 3 after injection. As shown in Figure 7(b), tumor volume of control group was rapidly increased with time course. Tumor growth of Ce6 treatment group was inhibited and then tumor volume was smaller than control group. In particular, tumor growth 


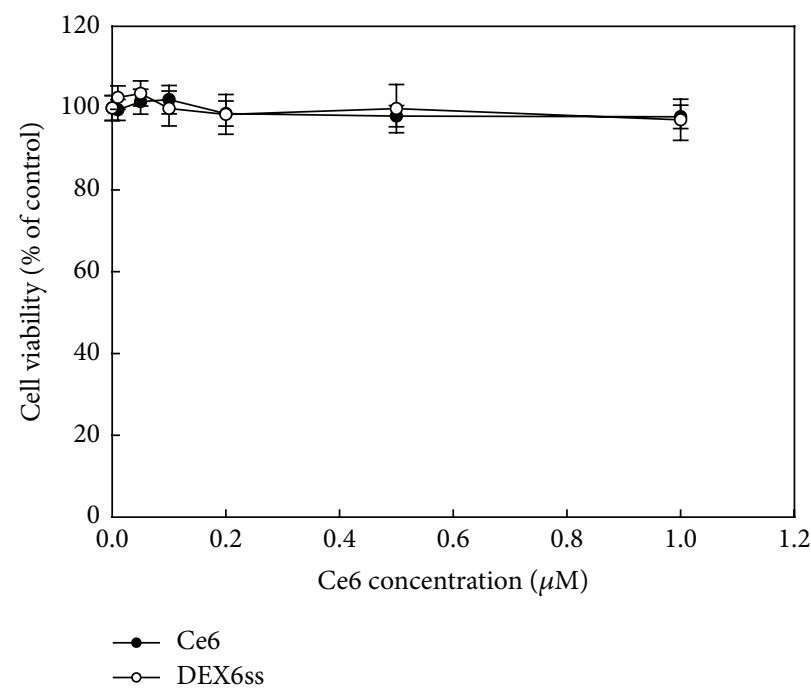

Figure 4: Dark toxicity of DEX6ss nanoparticles. Dark toxicity of DEX6ss nanoparticles was evaluated with HCT116 cells in the absence of light. Ce6 or DEX6ss nanoparticles were exposed to cancer cells for $2 \mathrm{~h}$, washed with PBS, and incubated for $24 \mathrm{~h}$. The presented data was mean \pm s.d. from 8 wells of 96 -well plates.

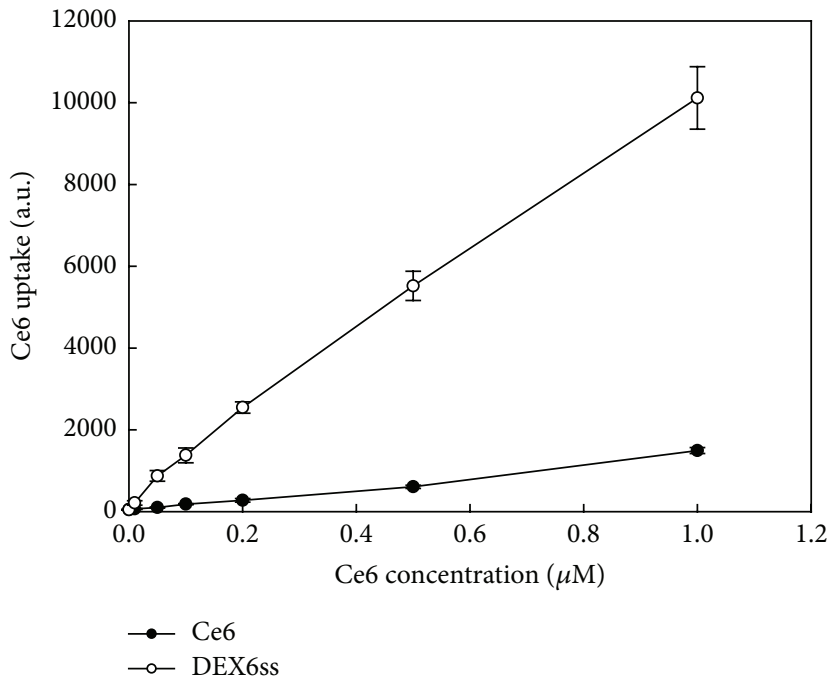

(a)
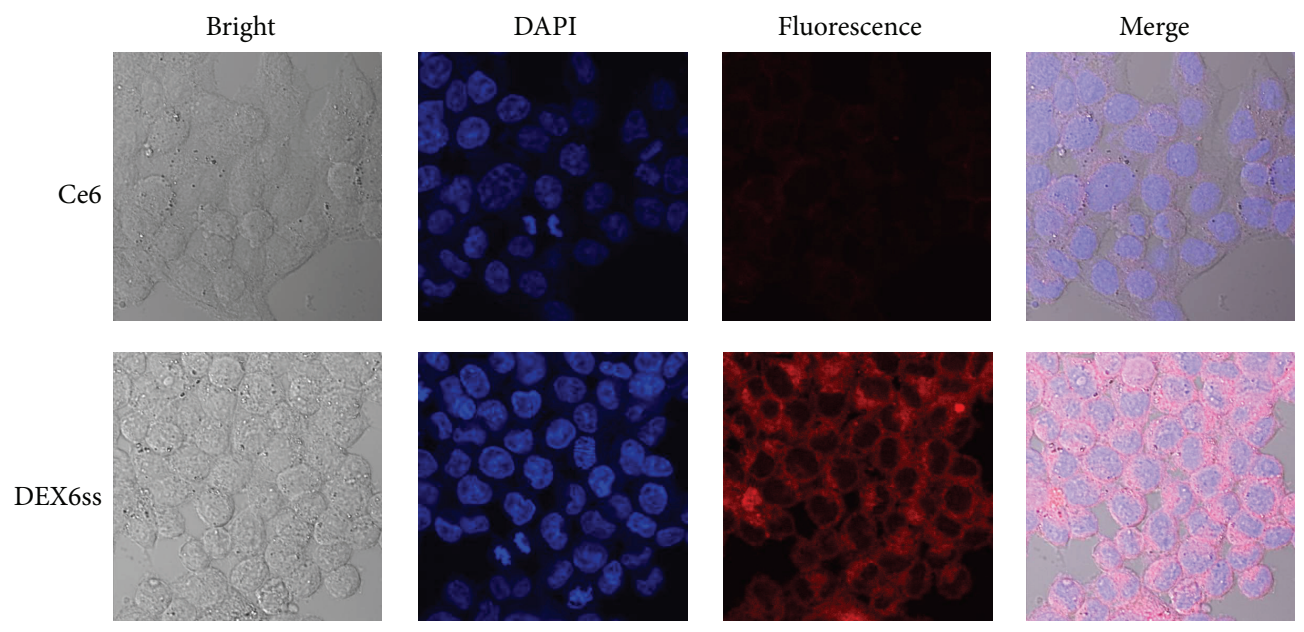

(b)

Figure 5: (a) Ce6 uptake and (b) fluorescence images of HCT116 cells. For measurement of Ce6 accumulation, cells were exposed to Ce6 or DEX6ss for $2 \mathrm{~h}$ and then cells were washed with PBS twice. Then, cells were lysed with lysis buffer for $1 \mathrm{~h}$ and then Ce6 concentration in cells was measured fluorometrically. Fluorescence images of cells were observed with CLSM. The presented data was mean \pm s.d. from 8 wells of 96-well plates. 


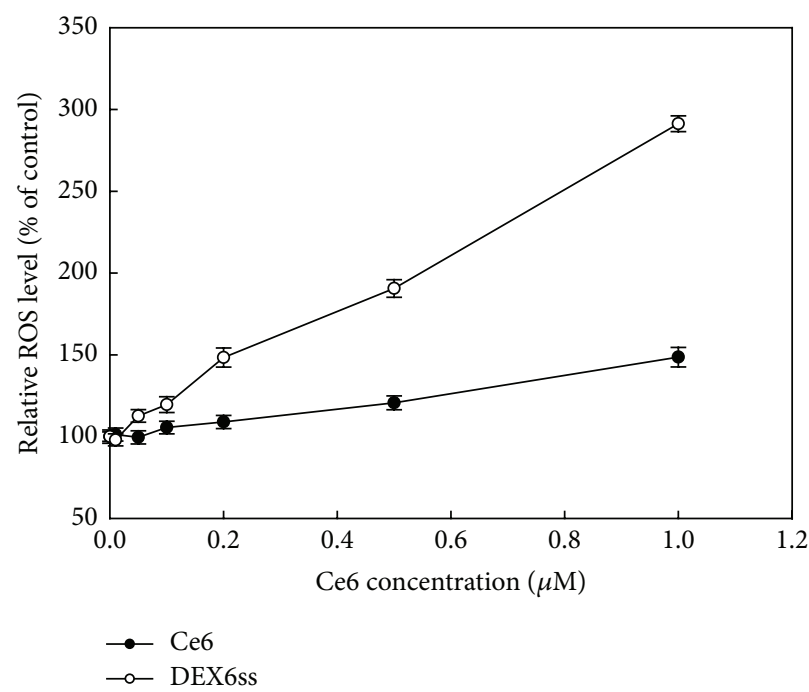

(a)

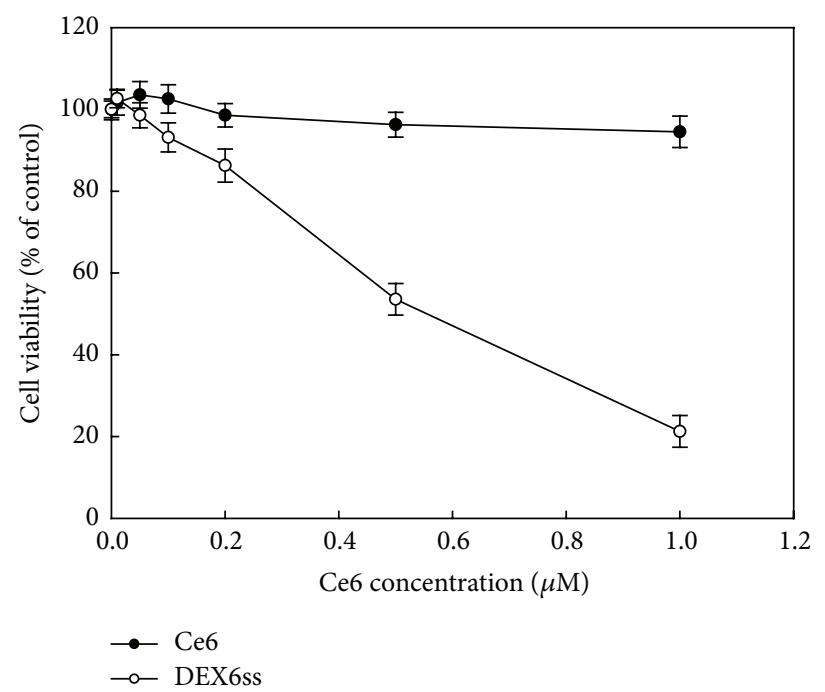

(b)

FIGURE 6: (a) ROS generation and (b) phototoxicity of DEX6ss nanoparticles. For ROS generation measurement, HCT116 cells were incubated with various concentration of Ce6 or DEX6ss nanoparticles for $2 \mathrm{~h}$ with DCFH-DA. Cell were washed with PBS and then $100 \mu \mathrm{L}$ phenol redfree RPMI media was added to each well following irradiation at $2.0 \mathrm{~J} / \mathrm{cm}^{2}$ light. ROS generation was measured based on fluorescence intensity and expressed as the percentage versus control. For phototoxicity measurement, cells were incubated with various concentrations of Ce6 or DEX6ss nanoparticles for $2 \mathrm{~h}$ and washed with PBS. Then, fresh media were added and irradiated with $2.0 \mathrm{~J} / \mathrm{cm}^{2}$ light. The presented data was mean \pm s.d. from 8 wells of 96 -well plates.

of DEX6ss nanoparticle treatment group was markedly inhibited and tumor volume was one-third of control group and less than half of Ce6 treatment group. Furthermore, difference in tumor growth inhibition between Ce6 treatment and DEX6ss nanoparticle treatment was statistically significant $(p<0.001)$. These results indicated that DEX6ss nanoparticles have superior PDT efficiency compared to Ce6 itself.

\section{Discussion}

Colon cancer is second and third most common malignancies in women and men, respectively [27]. Surgical removal is still regarded as an ideal approach in the early stage of colon cancer and the other treatment options including radiotherapy, adjuvant chemotherapy, or palliative chemotherapy are an alternative candidate when tumor region is not fully resectable $[27,28]$. However, radiotherapy and chemotherapy still have limitations in the clinic although these are principal therapeutic option for colon cancer treatment. For example, mobility of colon makes it difficult to define target during radiotherapy and colon is surrounded by dose-limiting structure such as bowel, kidney, and liver. In chemotherapy, chemotherapeutic agents frequently affected normal cells/tissues/organs such as bone marrow, hair follicles, lining of the mouth, and intestines even though they principally attack cancer cells/tissues and then inhibit its growth [29].

Since dextran can be degraded by dextranase in the colonic region, various polymeric conjugates, nanoparticles, and microspheres have been investigated using dextran [3035]. Swelling ratio of dextran hydrogel was increased 45 times in the presence of dextranase and 5-aminosalicylic acid release was also increased by degradation of dextran linkage as discussed by Kim and Oh [34]. Jianping et al. synthesized poly(sodium 4-styrene sulfonate)-grafted dextran and fabricated $\mathrm{pH}$-/enzyme-sensitive microspheres for 5-fluorouracil delivery to the colon [32]. They argued that microspheres released the drug a little in the $\mathrm{pH} 7.4$ and sudden delivery phenomenon of the drug occurred in the presence of dextranase while they did not release the drug in the acidic $\mathrm{pH}$ environment. Casadei et al. also reported that $\mathrm{pH}$-sensitive and enzymatic degradable dextran derivatives can be used to deliver the anticancer drug for colonic cancer [36]. Dextran can be used as a targetable device for disease in the colonic region and, especially, it is useful material for local treatment of colon cancer because nanoparticles are known to improve oral bioavailability 3.9fold at in vivo pharmacokinetics $[37,38]$. Xu et al. showed that nanoparticles significantly improved permeability of drug with in vitro transport study using Caco- 2 cells and it also improved transport in the rat ileum [38]. Furthermore, they also approved that nanoparticles selectively targeted tumor tissue in vivo colon tumor-xenograft study.

In this study, we designed DEX6ss conjugates for colonspecific and/or tumor-specific delivery of photosensitizer. Disulfide linkage was attached between Ce6 and dextran because disulfide bond is cleaved by intracellular GSH [39]. Redox-responsive based drug targeting using disulfide linkage was also extensively investigated since intracellular GSH level is known to increase significantly in cancer cells higher than normal cells, tissues, and extracellular fluid [39]. Nanoparticles having disulfide linkage are also known to increase drug targeting to cancer cells by specific disintegration of disulfide linkage in the intracellular GSH of cancer 

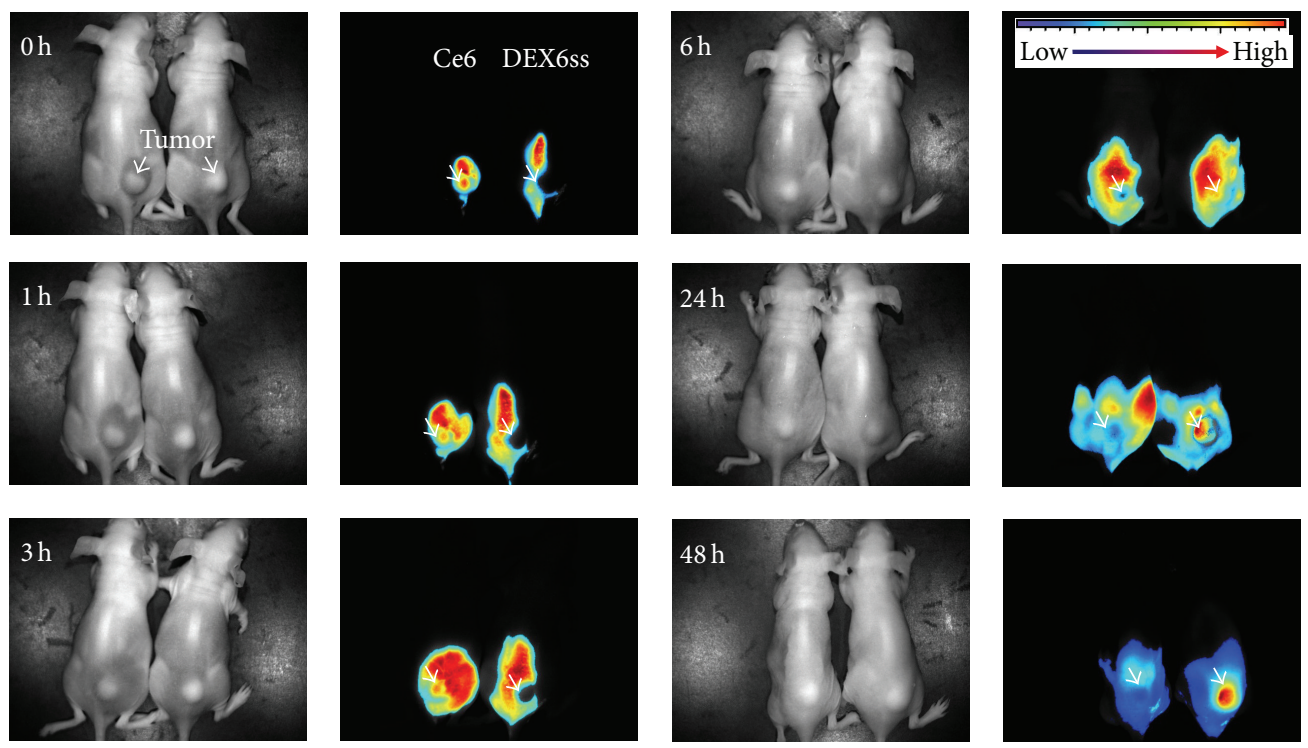

(a)

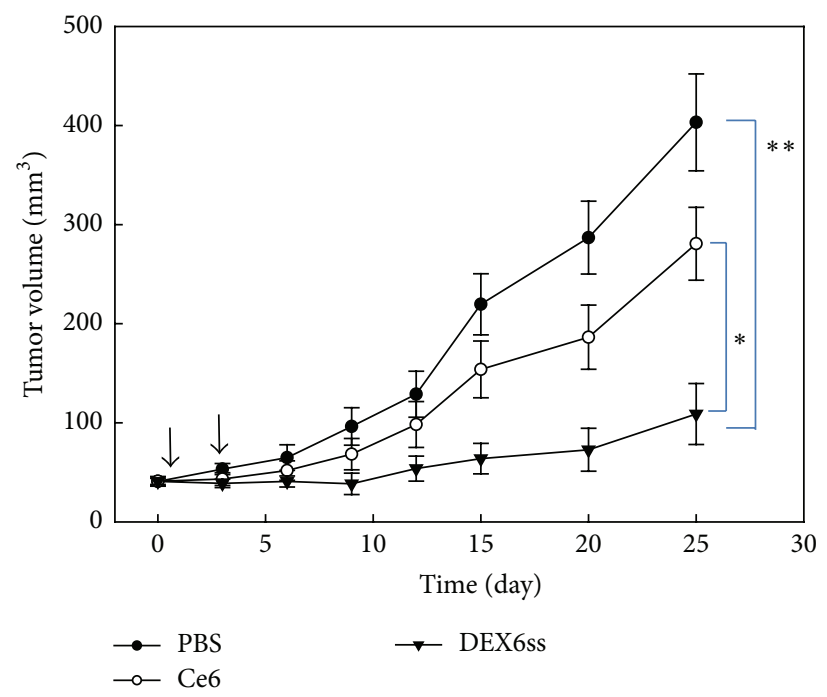

(b)

Figure 7: (a) Near Infrared florescence images and (b) tumor growth of HCT116 tumor-bearing mouse. $100 \mu \mathrm{L}$ of $1 \mathrm{mM}$ Ce6 or DEX6ss nanoparticles was injected subcutaneously beside the solid tumor. After that, fluorescence intensity in the tumor region was observed with in vivo fluorescence imaging system. For tumor growth inhibition study, $100 \mu \mathrm{L}$ of $1 \mathrm{mM}$ Ce6 or DEX6ss nanoparticles was injected subcutaneously to the back of mice. 2 days later after drug injection, mice were irradiated with a $2.0 \mathrm{~J} / \mathrm{cm}^{2}$. Tumor volume was measured in 3 4-day intervals. The difference in tumor growth inhibition between Ce6 treatment and DEX6ss nanoparticle treatment was statistically significant $(p<0.001)$. The presented data was mean \pm s.d. from 5 mice. ${ }^{* * * *} p<0.001$.

cells [40]. Vong et al. reported that redox-nanoparticles are specifically accumulated in the colon and they showed higher drug efficacy than low molecular weight drugs [41]. They also approved that redox-nanoparticles were specifically delivered to the cells in the inflamed region of colon and not internalized into the cells in the normal colon. We demonstrated that DEX6ss nanoparticles responded to colonic enzyme, dextranase, and GSH level as shown in Figure 3. Ce6 was released according to the presence of dextranase or GSH in the medium. DEX6ss nanoparticles significantly improved the intracellular delivery of photosensitizer against HCT116 cells in vitro and the tumor tissues in vivo at tumor xenograft study as shown in Figures 5, 6, and 7. They also stayed in the solid tumor tissue longer than Ce6 itself. DEX6ss nanoparticles efficiently inhibited tumor growth rather than Ce6 itself as shown in Figure 7.

In conclusion, we synthesized DEX6ss nanoparticles for specific targeting of solid tumor in the colonic region. Dextranase or GSH increased Ce6 release rate from DEX6ss nanoparticles via disintegration of dextran chain or disulfide 
linkage. Intracellular delivery was significantly improved with DEX6ss nanoparticles compared to Ce6 itself. ROS production and phototoxicity of DEX6ss nanoparticles were also markedly higher than Ce6 itself. At in vivo animal study with HCT116 tumor-bearing mice, DEX6ss nanoparticles showed enhanced tumor targeting efficiency and longer retention in the tumor tissues compared to Ce6. Furthermore, DEX6ss nanoparticles have responsiveness against colonic enzyme, dextranase, indicating that they have potential to colonspecific delivery through dextranase-mediated $\mathrm{Ce} 6$ delivery. We suggest that DEX6ss nanoparticles can be considered a promising candidate for PDT of colon cancer.

\section{Conflict of Interests}

The authors report no conflict of interests in this work.

\section{Acknowledgment}

This study was supported by Research Institute for Convergence of Biomedical Science and Technology (30-2015-015).

\section{References}

[1] D. E. J. G. J. Dolmans, D. Fukumura, and R. K. Jain, "Photodynamic therapy for cancer," Nature Reviews Cancer, vol. 3, no. 5, pp. 380-387, 2003.

[2] T. J. Dougherty, C. J. Gomer, B. W. Henderson et al., "Photodynamic therapy," Journal of the National Cancer Institute, vol. 90, no. 12, pp. 889-905, 1998.

[3] T. Y. Lee, Y. K. Cheon, and C. S. Shim, "Current status of photodynamic therapy for bile duct cancer," Clinical Endoscopy, vol. 46, no. 1, pp. 38-44, 2013.

[4] T. Y. Lee, Y. K. Cheon, C. S. Shim, and Y. D. Cho, "Photodynamic therapy prolongs metal stent patency in patients with unresectable hilar cholangiocarcinoma," World Journal of Gastroenterology, vol. 18, no. 39, pp. 5589-5594, 2012.

[5] K. S. McMahon, T. J. Wieman, P. H. Moore, and V. H. Fingar, "Effects of photodynamic therapy using mono-L-aspartyl chlorin e6 on vessel constriction, vessel leakage, and tumor response," Cancer Research, vol. 54, no. 20, pp. 5374-5379, 1994.

[6] N. Shishkova, O. Kuznetsova, and T. Berezov, "Photodynamic therapy in gastroenterology," Journal of Gastrointestinal Cancer, vol. 44, no. 3, pp. 251-259, 2013.

[7] B. W. Jia and X. L. Lian, "Use of photodynamic therapy in malignant lesions of stomach, bile duct, pancreas, colon and rectum," Hepato-Gastroenterology, vol. 54, no. 75, pp. 718-724, 2007.

[8] H. M. Lee, Y.-I. Jeong, D. H. Kim et al., "Ursodeoxycholic acidconjugated chitosan for photodynamic treatment of HuCCT1 human cholangiocarcinoma cells," International Journal of Pharmaceutics, vol. 454, no. 1, pp. 74-81, 2013.

[9] C. H. Kim, C.-W. Chung, K. H. Choi et al., "Effect of 5-aminolevulinic acid-based photodynamic therapy via reactive oxygen species in human cholangiocarcinoma cells," International Journal of Nanomedicine, vol. 6, pp. 1357-1363, 2011.

[10] B. Liu, T. J. Farrell, and M. S. Patterson, "Comparison of photodynamic therapy with different excitation wavelengths using a dynamic model of aminolevulinic acid-photodynamic therapy of human skin," Journal of Biomedical Optics, vol. 17, no. 8, Article ID 088001, 2012.

[11] J. J. Yoo, C. H. Kim, C.-W. Chung, Y.-I. Jeong, and D. H. Kang, "5-Aminolevulinic acid-incorporated poly(vinyl alcohol) nanofiber-coated metal stent for application in photodynamic therapy," International Journal of Nanomedicine, vol. 7, pp. 19972005, 2012.

[12] T. V. Akhlynina, D. A. Jans, N. V. Statsyuk et al., "Adenoviruses synergize with nuclear localization signals to enhance nuclear delivery and photodynamic action of internalizable conjugates containing chlorin $\mathrm{e}_{6}$, 'International Journal of Cancer, vol. 81, no. 5, pp. 734-740, 1999.

[13] W. G. Roberts, F.-Y. Shiau, J. S. Nelson, K. M. Smith, and M. W. Berns, "In vitro characterization of monoaspartyl chlorin e6 and diaspartyl chlorin e6 for photodynamic therapy," Journal of the National Cancer Institute, vol. 80, no. 5, pp. 330-336, 1988.

[14] M. T. Tarragó-Trani, S. Jiang, K. C. Harich, and B. Storrie, "Shiga-like toxin subunit B (SLTB)-enhanced delivery of chlorin e6 (Ce6) improves cell killing," Photochemistry and Photobiology, vol. 82, no. 2, pp. 527-537, 2006.

[15] D. Fuks, E. Bartoli, R. Delcenserie et al., "Biliary drainage, photodynamic therapy and chemotherapy for unresectable cholangiocarcinoma with jaundice," Journal of Gastroenterology and Hepatology, vol. 24, no. 11, pp. 1745-1752, 2009.

[16] B. Čunderlíková, L. Gangeskar, and J. Moan, "Acid-base properties of chlorin e6: relation to cellular uptake," Journal of Photochemistry and Photobiology B: Biology, vol. 53, no. 1-3, pp. 8190, 1999.

[17] J. D. Spikes, "Chlorins as photosensitizers in biology and medicine," Journal of Photochemistry and Photobiology B, vol. 6, pp. 259-274, 1990.

[18] M. Ali-Seyed, R. Bhuvaneswari, K. C. Soo, and M. Olivo, "Photolon-photosensitization induces apoptosis via ROSmediated cross-talk between mitochondria and lysosomes," International Journal of Oncology, vol. 39, no. 4, pp. 821-831, 2011.

[19] F.-Q. Hu, X.-H. Jiang, X. Huang et al., "Enhanced cellular uptake of chlorine e6 mediated by stearic acid-grafted chitosan oligosaccharide micelles," Journal of Drug Targeting, vol. 17, no. 5, pp. 384-391, 2009.

[20] H. Jeong, M. Huh, S. J. Lee et al., "Photosensitizer-conjugated human serum albumin nanoparticles for effective photodynamic therapy," Theranostics, vol. 1, pp. 230-239, 2011.

[21] H. Park and K. Na, "Conjugation of the photosensitizer Chlorin e6 to pluronic F127 for enhanced cellular internalization for photodynamic therapy," Biomaterials, vol. 34, no. 28, pp. 69927000, 2013.

[22] J.-H. Hwang, C. W. Choi, H.-W. Kim et al., "Dextran-b-poly(Lhistidine) copolymer nanoparticles for $\mathrm{pH}$-responsive drug delivery to tumor cells," International Journal of Nanomedicine, vol. 8, pp. 3197-3207, 2013.

[23] Y.-I. Jeong, D. H. Kim, C.-W. Chung et al., "Doxorubicinincorporated polymeric micelles composed of dextran-bpoly(DL-lactide-co-glycolide) copolymer," International Journal of Nanomedicine, vol. 6, pp. 1415-1427, 2011.

[24] Y. I. Jeong, K. D. Chung, D. H. Kim, Y. H. Kim, Y. S. Lee, and K. C. Choi, "All-trans retinoic acid-incorporated nanoparticles of deoxycholic acid-conjugated dextran for treatment of CT26 colorectal carcinoma cells," International Journal of Nanomedicine, vol. 8, pp. 485-493, 2013.

[25] I.-S. Kim, Y.-L. Jeong, D.-H. Kim, Y.-H. Lee, and S.-H. Kim, "Albumin release from biodegradable hydrogels composed of 
dextran and poly(ethylene glycol) macromere," Archives of Pharmacal Research, vol. 24, no. 1, pp. 69-73, 2001.

[26] D. H. Kim, M.-D. Kim, C.-W. Choi et al., "Antitumor activity of sorafenib-incorporated nanoparticles of dextran/poly(DLlactide-co-glycolide) block copolymer," Nanoscale Research Letters, vol. 7, no. 1, article 91, 2012.

[27] J. H. Kim, "Chemotherapy for colorectal cancer in the elderly," World Journal of Gastroenterology, vol. 21, no. 17, pp. 5158-5166, 2015.

[28] B. Chibaudel, C. Tournigand, T. André, and A. de Gramont, "Therapeutic strategy in unresectable metastatic colorectal cancer," Therapeutic Advances in Medical Oncology, vol. 4, no. 2, pp. 75-89, 2012.

[29] C. G. Moertel, "Chemotherapy for colorectal cancer," The New England Journal of Medicine, vol. 330, no. 16, pp. 1136-1142, 1994.

[30] H. Basan, M. Gümüşderelioğlu, and M. Tevfik Orbey, "Release characteristics of salmon calcitonin from dextran hydrogels for colon-specific delivery," European Journal of Pharmaceutics and Biopharmaceutics, vol. 65, no. 1, pp. 39-46, 2007.

[31] K. Ichinose, N. Tomiyama, M. Nakashima et al., "Antitumor activity of dextran derivatives immobilizing platinum complex (II)," Anti-Cancer Drugs, vol. 11, no. 1, pp. 33-38, 2000.

[32] Z. Jianping, G. Jianfeng, Z. Yao, and Y. Jiao, "Preparation and characterization of cross-linked microspheres C(Dex-g-PSSS) and their drug-carrying and colon-specific drug delivery properties," Journal of Biomaterials Science, Polymer Edition, vol. 25, no. 16, pp. 1828-1841, 2014.

[33] S.-W. Jung, Y.-I. Jeong, Y.-H. Kim, K.-C. Choi, and S.-H. Kim, "Drug release from core-shell type nanoparticles of poly(DLlactide-co-glycolide)-grafted dextran," Journal of Microencapsulation, vol. 22, no. 8, pp. 901-911, 2005.

[34] I.-S. Kim and I.-J. Oh, "Drug release from the enzymedegradable and $\mathrm{pH}$-sensitive hydrogel composed of glycidyl methacrylate dextran and poly(acrylic acid)," Archives of Pharmacal Research, vol. 28, no. 8, pp. 983-987, 2005.

[35] G. Rai, A. K. Yadav, N. K. Jain, and G. P. Agrawal, "Entericcoated epichlorohydrin crosslinked dextran microspheres for site-specific delivery to colon," Drug Development and Industrial Pharmacy, vol. 41, no. 12, pp. 2018-2028, 2015.

[36] M. A. Casadei, G. Pitarresi, R. Calabrese, P. Paolicelli, and G. Giammona, "Biodegradable and $\mathrm{pH}$-sensitive hydrogels for potential colon-specific drug delivery: characterization and in vitro release studies," Biomacromolecules, vol. 9, no. 1, pp. 43-49, 2008.

[37] M. Tariq, M. A. Alam, A. T. Singh, Z. Iqbal, A. K. Panda, and S. Talegaonkar, "Biodegradable polymeric nanoparticles for oral delivery of epirubicin: in vitro, ex vivo, and in vivo investigations," Colloids and Surfaces B: Biointerfaces, vol. 128, pp. 448-456, 2015.

[38] G. Xu, C. Shi, D. Guo et al., "Functional-segregated coumarincontaining telodendrimer nanocarriers for efficient delivery of SN-38 for colon cancer treatment," Acta Biomaterialia, vol. 21, pp. 85-98, 2015.

[39] F. Q. Schafer and G. R. Buettner, "Redox environment of the cell as viewed through the redox state of the glutathione disulfide/glutathione couple," Free Radical Biology \& Medicine, vol. 30, no. 11, pp. 1191-1212, 2001.

[40] H. Sun, B. Guo, R. Cheng, F. Meng, H. Liu, and Z. Zhong, "Biodegradable micelles with sheddable poly(ethylene glycol) shells for triggered intracellular release of doxorubicin," Biomaterials, vol. 30, no. 31, pp. 6358-6366, 2009.
[41] L. B. Vong, T. Tomita, T. Yoshitomi, H. Matsui, and Y. Nagasaki, "An orally administered redox nanoparticle that accumulates in the colonic mucosa and reduces colitis in mice," Gastroenterology, vol. 143, no. 4, pp. 1027-e3, 2012. 

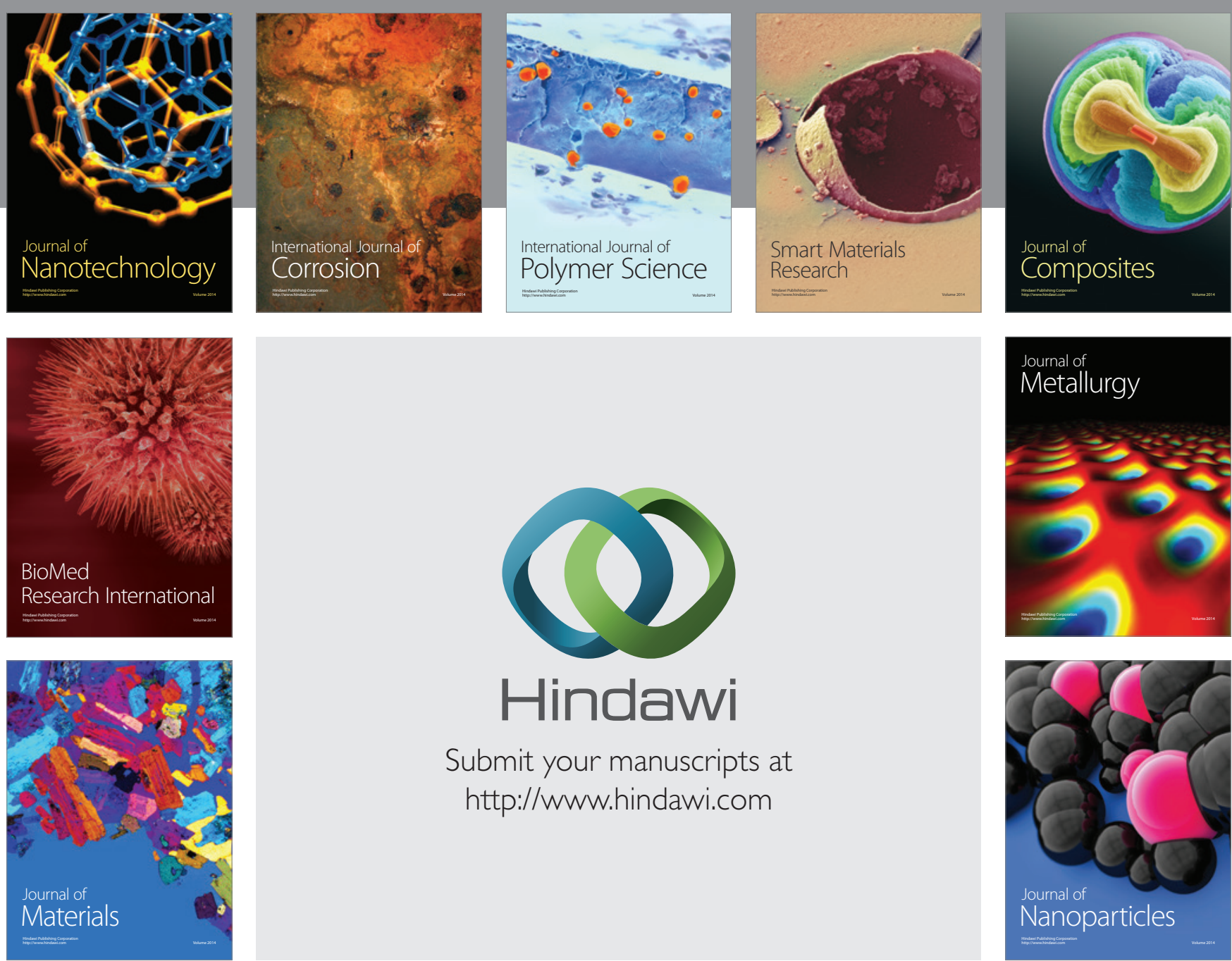

\section{Hindawi}

Submit your manuscripts at

http://www.hindawi.com

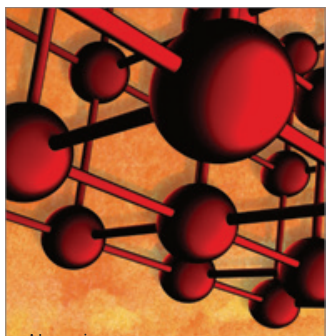

Materials Science and Engineering
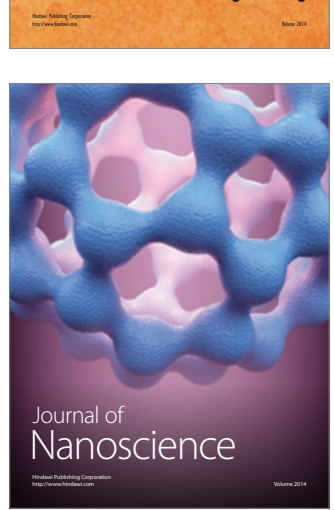
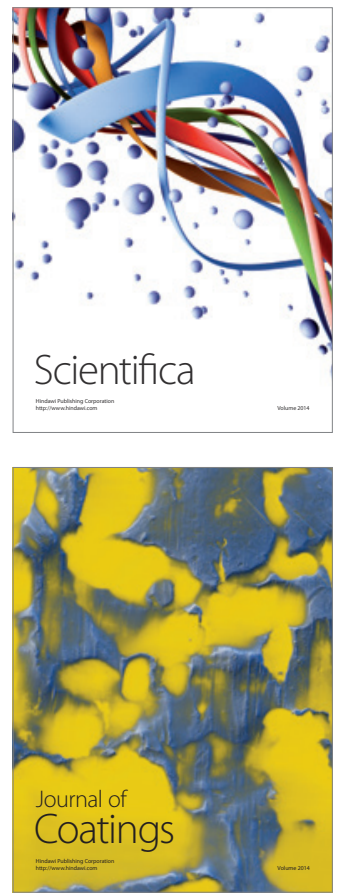
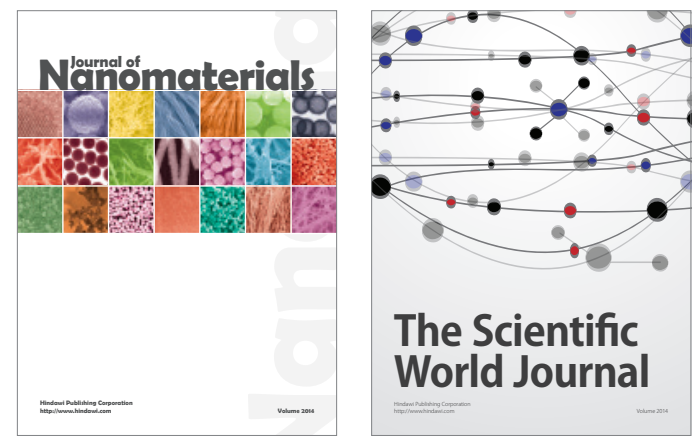

The Scientific World Journal
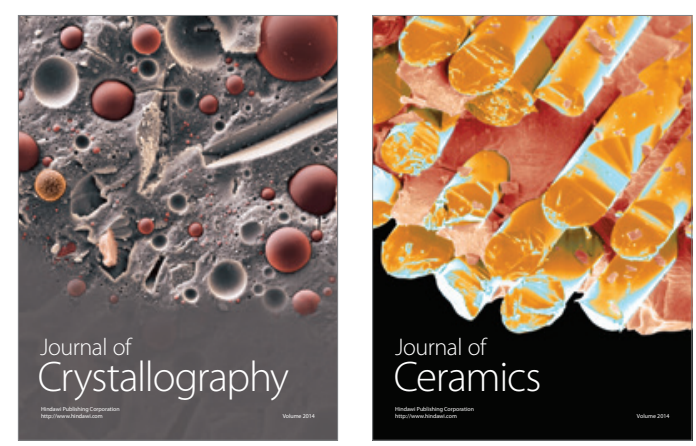
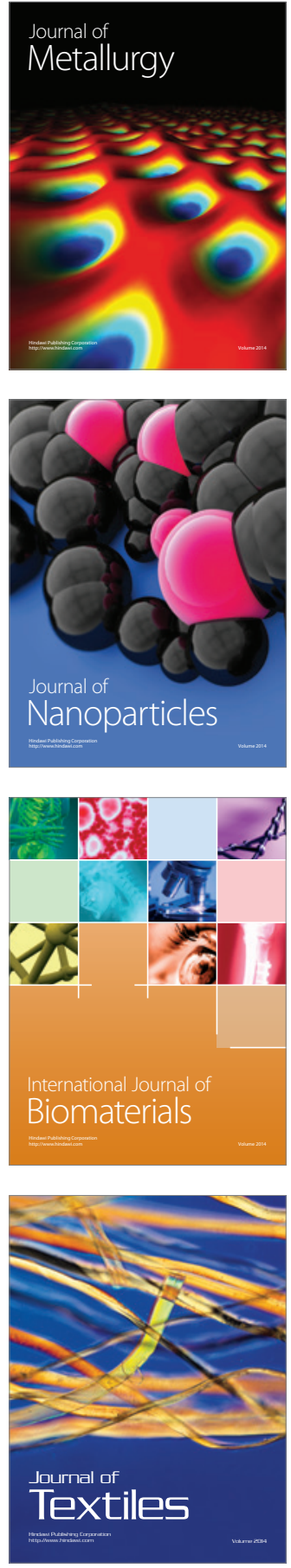